Sein-Echaluce, M. L., Fidalgo-Blanco, Á., \& García-Peñalvo, F. J. (2017). Adaptive and cooperative model of knowledge management in MOOCs. In P. Zaphiris \& A. loannou (Eds.), Learning and Collaboration Technologies. Technology in Education. 4th International onference, LCT 2017. Held as Part of HCI International 2017, Vancouver, BC, Canada, July 9-14, 2017. Proceedings, Part I (pp. 273-284). Switzerland: Springer International Publishing. doi:10.1007/978-3-319-58509-3_22

The final publication is available at link.springer.com

\title{
Adaptive and cooperative model of knowledge management in MOOCs
}

María Luisa Sein-Echaluce ${ }^{1}$, Ángel Fidalgo-Blanco ${ }^{2}$, Francisco J. García-Peñalvo ${ }^{3}$

\author{
${ }^{1}$ University of Zaragoza, Zaragoza, Spain \\ mlsein@unizar.es \\ ${ }^{2}$ Technical University of Madrid, Madrid, Spain \\ angel.fidal go@pm es \\ ${ }^{3}$ GRIAL Research Group. University of Salamanca, Salamanca, Spain \\ fgarcia@us al.es
}

\begin{abstract}
One of the characteristics of Massive Open Online Courses (MOOC) is the heterogeneity of their participants' profiles and, for the most traditional MOOC model, this is an important cause of the low completion rate. The MOOC model presents two apparent antagonistic concepts, globalization and diversity. MOOCs represent globalization (participants have to be adapted to the course) and their participants represent diversity. The authors of this paper argue that both concepts complement each other; that is, a MOOC can adapt the contents and navigation to the diversity of participants; and in turn the participants themselves can increase and improve the contents of the MOOC, through heterogeneous cooperation, to encourage massive learning. To proof it, this paper presents a new model, called ahMOOC, combining the hybridMOOC (hMOOC) and the adaptive MOOC (aMOOC). The hMOOC allows integrating characteristics of xMOOCs (based on formal e-training) with cMOOCs (based on informal and cooperative e-training). The aMOOC offers different learning strategies adapted to different learning objectives, profiles, learning styles, etc. of participants. The ahMOOCs continues having a lower dropout rate (such as hMOOC) than the traditional MOOCs. The qualitative analysis show the capacity of participants, with heterogeneous profiles, to create, in a cooperative and massive way, useful knowledge to improve the course and, later, to apply it in their specific work context. The study also shows that participants have a good perception on the capabilities of the ahMOOC to adapt the learning process to their profiles and preferences.
\end{abstract}

Keywords: Adaptive learning, Massive open online course, Online learning, Learning management system 


\section{Introduction}

The most commonly used Massive Open Online Courses (MOOCs), called xMOOCs, have a structure very similar to academic online courses (with similar platforms, methodologies and objectives).

The educational model is based on a traditional academic model (formal learning): content organization into modules with objectives, descriptive videos and evaluation activities (tests and academic works). In spite of this, there are very significant differences with the traditional education models: heterogeneity and overcrowding. A type X MOOC can have thousands of enrolled people with a very heterogeneous profile.

The thousands of participants are multicultural (from dozens of different countries), intergenerational (all age ranges), with different objectives (which do not always coincide with the initials ones), plurality of professions and roles in a specific context (in education: teachers, students, managers, professionals, retirees, etc.), with different academic grades (from basic levels of studies to doctorate) [1].

In the formal education processes, participants have restrictions and conditions in the courses and the most important are the number of attendees and the required previous knowledge.

The number of attendees is usually predefined in each course, academic area and country. Usually a maximum number of people per course is fixed. This is because overcrowding is an aspect related to learning outcomes.

The other conditioning aspect is the required previous knowledge that is necessary to attend a particular course. This prior knowledge is usually conditioned by academic certifications, which require the passing of certain subjects, or a level of studies such as, for example, to start university studies.

However, in the XMOOCs created by universities these limitations are not contemplated. There is no limit on the number of participants in a MOOC and there are no demands on the required academic levels.

Thus, in xMOOCs use usual platforms and educational methods of online learning, but without the limitations of overcrowding, educational level, age, or even academic degree. These conditions have often been mentioned as the main causes of the very high dropout rate and learning failure associated with MOOCs (between 90\% and 95\%).

Previous research works seek to improve the success of xMOOCs by combining strategies of cMOOCs (based on connectivism and incorporating cooperative work) with those of type X. These MOOCs are called hybrid MOOCs (hMOOCs) [2].

Other important line is based on personalized learning, one of the important trends in Educational Technology for Higher Education according to NMC Horizon Report: 2017 Higher Education Edition [3], which applies different learning techniques depending on the characteristics of the participants. But to carry out such personalization, the use of a technological systems is essential, taking into account its capabilities regarding adaptability (the participant chooses within the system according to its characteristics) and adaptivity (the system decides depending on the characteristics of the participant) [4-5]. 
We are going to denominate Adaptivity to the capacity of a system to facilitate the two previous options. But the educational model must also have these characteristics in order to allow the technology will be effective. This way, an adaptation to the great heterogeneity of the participants is achieved. The MOOCs that present functionalities and adaptive models are called adaptive MOOCs (aMOOCs) [6].

The hMOOCs integrate Learning Content Management Systems (LCMS) platforms with social networks, as well as formal and informal educational methods [7-8] and learning designs based on instructivism and connectivism [9].

On the other hand, aMOOCs have adaptive platforms that allow different kinds of personalization such as self-assessment training, adapted to the student's learning speed, adaptation of learning to different profiles / skills / interests, contributing and sharing resources among a set of users with a common interest / profile, adapted learning to the acquired knowledge (the results of the activities to be carried on), monitoring student's progress [6].

As a common nexus, the hMOOC and aMOOC proposals aim are intended to provide new models to reduce the dropout rate, taking into account both the overcrowding and the heterogeneity of its participants.

This paper aims to integrate the hMOOC and aMOOC models by adding a new characteristic component of knowledge management: integrating a bureaucratic organization (represented by the common and global aspects of the MOOC) with a creative force type organization (represented by the diversity of profiles, objectives and implementation needs) [10].

The idea behind this research is that overcrowding and heterogeneity can be used as drivers to improve learning. This approach contrasts with the current vision of both face-to-face and on-line education, where overcrowding and heterogeneity are aspects that negatively influence the learning process.

The main objective of this work is to obtain a first prototype where it will be possible to show that the participants in a MOOC, with heterogeneous profiles, can create, in a cooperative and massive way, useful knowledge to improve the course and, later, to apply it in their specific work context.

The main contribution of this paper may be summarized in the following ones:

- A new MOOC model combining hMOOC and aMOOC, called ahMOOC. It presents a technological framework with a prototype.

- An analysis of the participants' capabilities to create knowledge that improves the MOOC itself. This ability to create knowledge would be independent of their academic or professional profile, and their objectives regarding the MOOC.

- The multicultural and heterogeneous perception of the participants, to apply, outside the context of the MOOC, the acquired knowledge in the course itself, as well as the resources created by other participants, even if they do not share the same academic or professional profile or the same objectives about the MOOC.

- The participants' perception about the adaptive characteristics of the ahMOOC, which allow a course with a global design to be adapted to the diversity of participants' profiles. 
The rest of the paper is organized as follows: Section 2 describes the proposed model and Section 3 presents the context where the prototype was built and the experience was realized. Section 4 includes the results of the experience. Finally, Sections 5 and 6 include the discussion of the results and conclusions of the work.

\section{Conceptual model of ahMOOC}

The proposed model is based on the integration of two already validated models by the authors of this work. The first model is the hMOOC [2] that has been tested on the MiriadaX platform throughout 7 MOOCs (20,000 students). This model includes the characteristics of both xMOOCs and cMOOCs types [1]. The second model, which has been also developed by the authors, is the aMOOC model. This model is experimental and has been validated during the 2015-2016 academic year through 4 aMOOCs interconnected throughout the virtual campus iMOOC [6].

The ahMOOCs are the result of the integration of both models, achieving resourcebased MOOCs, supported by social networks and adaptive systems.

\subsection{Methodological model}

Figure 1 shows an overview of the model that is composed of four parts, all integrated with each other, but with specific and distinct missions.

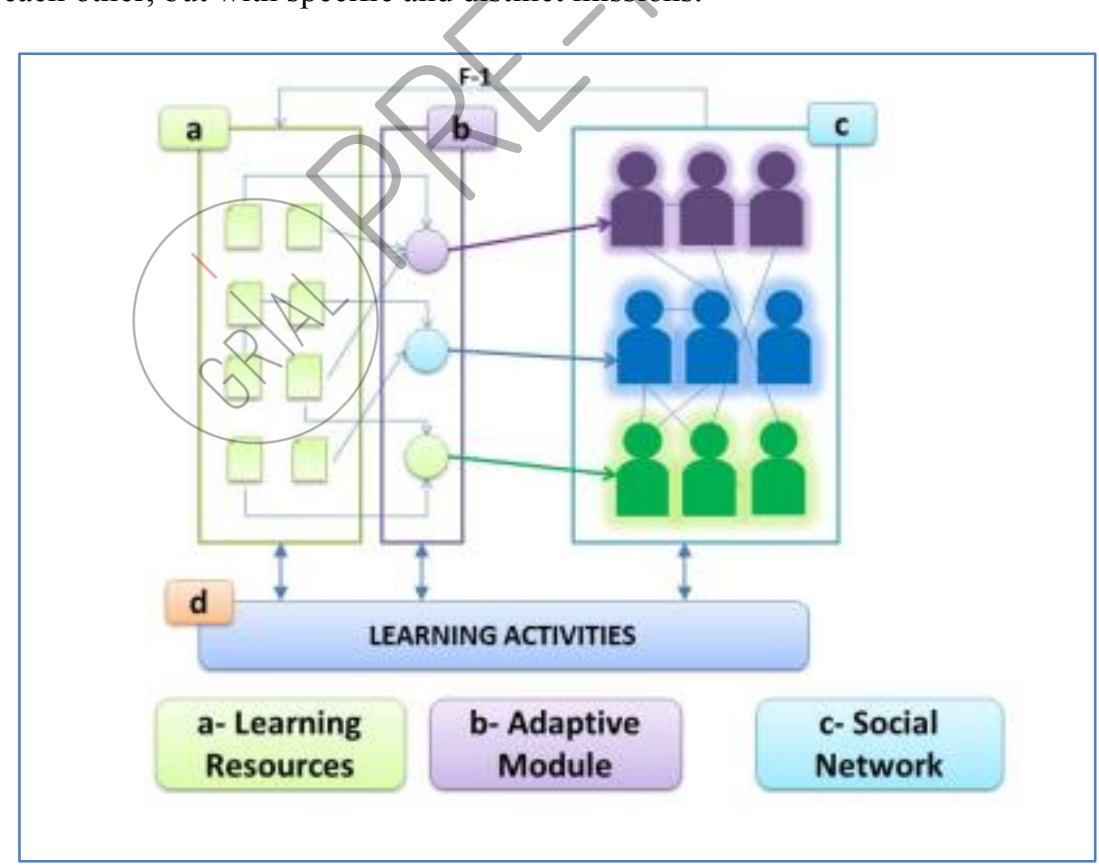

Fig. 1. General view of the proposed model 
Figure 1-a represents the learning resources of the course. The organization of the resources is based on xMOOCs. That is, the contents are organized in modules and sections, following a hierarchical structure as an index. The main difference is that in the proposed model resources are conditioned. Conditional resources are configured as accessible depending on whether a set of conditions are met, resulting from the user's interaction with the course contents.

Figure 1-b represents the adaptive module. This module is responsible for interacting with users and, depending on this interaction, selecting the most appropriate resources for each user profile [11]. Thus, it is able to establish different resources and activities based on adaptive processes such as previous knowledge, learning outcome or user profile. This module includes the adaptive indicators of a construct, already validated in a previous work through the perception of participants about the importance of including adaptive actions in the MOOCs [12].

Figure 1-c represents the students and the social networks. Unlike other MOOC models, the student profile is taken into account for the realization of the learning process. Both the learning resources and the activities to be carried out may depend on several factors that are associated with the user profile or their educational interests. Also, all users share the same social network, where they can interact with each other, regardless of the profiles.

There exists a duality where, from formal education, they receive specific and concrete resources for each situation, but on the other hand, all of them share a common space where they can exchange resources, information and contacts. The social network remarkable feature is the ability to allow asynchronous communications around the shared resources. For this reason, it can be used from a forum to a social network to carry out this activity.

Figure 1-d represents the learning activities. They could be of any type; the remarkable thing is that there are activities that are done specifically by a group of users and whose results are shared in the same group; by the way, other activities are carried out on the social network and these are shared with all users. rivers. The result of the developed actixities in the MOOC can be shared in social networks and on the contrary also. That is, the result of activities in social networks can be shared in the MOOC too. This transfer of knowledge is represented by the data flow "F-1" in Figure 1. The resources that pass from the social network to the MOOC are reviewed, filtered and selected by the teaching staff.

\subsection{Technological model}

The technological model is based on the technological framework presented by the same authors [9] and is based on a technological ecosystem [13-14], where modules may be added to interact with each other sharing learning resources and integrating technologies. In this case, the proposed ecosystem includes an eLearning platform, an adaptive module, a social web component and a knowledge management system.

The eLearning system is based on the Moodle platform [15], which allows to organize the resources and activities under a classic model of a xMOOC. The adaptive module is implemented in the own Moodle through techniques and processes 
that allow to detect different adaptive processes. The platform where the adaptive module is integrated and the eLearning system is called iMOOC. The social web module is comprised of a social network in Google+, where useful resources and the results of the course activities are provided; also, a blog to post reflections is available.

\section{Context of the experience}

The presented research has been carried out from the data obtained in the first edition of the "iMOOC" campus about Educational Innovation, developed during the last quarter of 2015 and the first of 2016.

This campus is made up of four related aMOOCs, since the topics covered in each aMOOC are complementary to the application of educational innovation. The four aMOOCs are as follows:

- PFEI - Practical Fundamentals of Educational Innovation [16].

- $\quad$ FT - Flip Teaching [17].

- LC - Learning Communities [18].

- TWCD - TeamWork Competence Development [19].

PFEI gives the conceptual support to any application of educational innovation, therefore it is related to the rest of the aMOOCs due to it allows to provide the bases of any educational innovation.

FT works with the Flip Teaching methodology, which can be applied to any learning situation, for example with teamwork and with learning communities.

LC allows the use of learning communities as a learning objective or as a complement to other methodologies of educational innovation.

TWCD allows apply teamwork to any other educational methodology.

Thus, MOOCs are related, but can also be done independently.

Below are some results of this implementation, starting with the completion rates in the four aMOOCs and the data collected throughout an opinion survey, filled out by the participants who completed each of the aMOOCs.

\section{$4 \quad$ Results}

\subsection{Completion rate}

In this edition, 870 people with different profiles and belonging to 27 different countries have been registered, with a majority distribution in Spanish-speaking countries. In addition, participants present a great diversity in terms of profession, academic degree, previous experience and motivation to participate in the MOOC $[6$, 11-12].

Table 1 shows the number of participants in each MOOC, ending rate (the completion is obtained when all the evaluation activities have been carried out), and the type of evaluation activity that has been completed in each MOOC. 
Evaluation activities include forums or learning communities where interacting, sharing contents or delivering the final project of the course. This final project is an action plan where the participants should apply the acquired knowledge in the MOOC to their future work.

Table 1. Number of participants, completed and surpassed in each aMOOC

\begin{tabular}{c|c|c|c}
\hline aMOOC $\backslash$ Role & Participants & Ending rate (\%) & Evaluation activity \\
\hline LC & 203 & 27.09 & Project making and community \\
TWCD & 87 & 55.17 & Forums of opinion and content sharing \\
FT & 162 & 25.93 & Video tuning and project making \\
PFEI & 209 & 26.32 & Project making \\
\hline Global & 661 & 30.26 & \\
\hline
\end{tabular}

From a global perspective, the $30.26 \%$ of enrolled students completed different MOOCs and, individually, the completion rate exceeded $25 \%$ in all courses.

\subsection{Opinion poll}

A final survey was made to the participants of the different MOOCs based on the modified SEEQ model for MOOC [9], which studies the dimensions: Learning (5 questions), Enthusiasm (4 questions), Contents (3 questions) (5 questions) and Workload (4 questions). Moreover, questions on adaptivity were included in the Organization dimension.

We have chosen a representative question of each of the firsts three dimensions: Learning (Q1), Enthusiasm (Q2) and Contents (Q3) and 3 questions on adaptivity (Q4, Q5 and Q6) that are included in the Organizational dimension. The choice was made based on the initial research work goal (the creation of useful knowledge), application of knowledge and adaptivity indicators.

The answers have been organized based on the Likert 4 scale (1-none agree, 2somewhat agree, 3-fairly agree and 4 agree). The values (in percentage) of the questions in each aMOOC are included. All the questions that are presented in this work have been made in all aMOOC. The number of valid responses for each aMOOC has been 57 for CA, 57 for TE, 43 for FE and 46 for FPIE, and in all cases, they exceed $100 \%$ of participants who completed the activity successfully.

Table 2 shows the percentage of responses for each value of the Likert scale for question Q1: "In this course, I have learned things that I consider valuable", which is representative of the Learning dimension. Table 3 shows the answers for question Q2: "The way of presenting the contents keeps my attention" that represents the Enthusiasm dimension. Table 4 shows the answers to question Q3: "The provided information by the participants in the forums has been useful to assimilate concepts", which is representative of the Content dimension. 
Table 2. Percentage of answers to question Q1 for each aMOOC

\begin{tabular}{c|c|c|c|c}
\hline aMOOCLikert & 1 & 2 & 3 & 4 \\
\hline LC & 1.75 & 1.75 & 31.58 & 64.71 \\
TWCD & 0 & 2.17 & 21.74 & 76.09 \\
FT & 0 & 0 & 25.58 & 74.42 \\
PFEI & 0 & 1.75 & 29.82 & 68.42 \\
\hline
\end{tabular}

Table 3. Percentage of answers to question Q2 for each aMOOC

\begin{tabular}{c|c|c|c|c}
\hline aMOOC $\backslash$ Likert & 1 & 2 & 3 & 4 \\
\hline LC & 0 & 12.28 & 36.84 & 50.68 \\
TWCD & 0 & 10.87 & 30.43 & 58.7 \\
FT & 0 & 4.65 & 18.6 & 76.74 \\
PFEI & 0 & 10.53 & 43.86 & 45.61 \\
\hline
\end{tabular}

Table 4. Percentage of answers to question Q3 for each aMOOC

\begin{tabular}{c|c|c|c|c}
\hline aMOOCLikert & 1 & 2 & 3 & 4 \\
\hline LC & 5.26 & 24.56 & 35.09 & 35.09 \\
TWCD & 6.52 & 26.09 & 29.13 & 28.26 \\
FT & 4.65 & 18.6 & 32.56 & 44.19 \\
PFEI & 3.51 & 22.81 & 52.63 & 21.05 \\
\hline
\end{tabular}

Tables 5 and 6 show the answers for question Q4: "The generation of a course that fits the participant's interests has been well designed" and for question Q5: "Making the resources visible according to my learning pace has helped me", which are related to adaptivity. Table 7 presents the answers to question Q6: "The proposed activities generate material that is usefulafter the course ends", which is about the usefulness of the application of the proposed tasks. These three questions are representative of the Organization dimension.

Table 5. Percentage of answers to question Q4 for each aMOOC

\begin{tabular}{c|c|c|c|c}
\hline aMOOC $\backslash$ Likert & 1 & 2 & 3 & 4 \\
\hline LC & 0 & 5.26 & 31.58 & 63.16 \\
TWCD & 0 & 2.17 & 39.13 & 58.7 \\
FT & 0 & 2.33 & 25.58 & 72.09 \\
PFEI & 0 & 7.02 & 26.32 & 66.67 \\
\hline
\end{tabular}


Table 6. Percentage of answers to question Q5 for each aMOOC

\begin{tabular}{c|c|c|c|c}
\hline aMOOClLikert & 1 & 2 & 3 & 4 \\
\hline LC & 0 & 8.77 & 24.56 & 66.67 \\
TWCD & 2.17 & 2.17 & 17.39 & 78.26 \\
FT & 0 & 2.33 & 25.58 & 72.09 \\
PFEI & 3.51 & 3.51 & 29.82 & 63.16 \\
\hline
\end{tabular}

Table 7. Percentage of answers to question Q6 for each aMOOC

\begin{tabular}{c|c|c|c|c}
\hline aMOOC\Likert & 1 & 2 & 3 & 4 \\
\hline LC & 0 & 8.77 & 29.82 & 61.4 \\
TWCD & 4.35 & 10.87 & 34.78 & 50 \\
FT & 4.65 & 0 & 25.58 & 69.77 \\
PFEI & 0 & 8.77 & 29.82 & 61.4 \\
\hline
\end{tabular}

\section{Discussion}

The technological framework is based on the model proposed by the authors in an earlier publication [9]. The supposed flexibility of this model is demonstrated in this work due to it is successfully applied in MOOCs, which integrate innovative features of other models such as hMOOC and aMOOC. Therefore, it demonstrates the versatility and applicability of the proposed technological framework.

Likewise, the proposed model has achieved an average of $30 \%$ final results, which represents a considerable difference over the common success rate in xMOOCs, which is between $5 \%$ and $10 \%$ [1].

Regarding the completion rate, we can compare the results of the PFEI aMOOC with MOOCs with the same contents, which was performed in MiriadaX with an exclusively hMOOC model. The completion mean of the hMOOCs was $25.16 \%$ versus $26.32 \%$ of the new model performed in this study.

The percentages are similar, however there exists a very important difference. While the evaluation activities in the MiriadaX platform courses are simple tests in each module, in this proposal, the evaluation consisted in the elaboration of a final project the included activities and applied knowledge of each of the modules. Therefore, although the completion rate is very similar, the difficulty and complexity to complete the proposed MOOCs in this model is much greater.

Another comparable aspect is the SEEQ survey about learning. For example, in MiriadaX hMOOC the question about learning was $54.38 \%$ "completely in agreement" [9] compared to $68.42 \%$ in the equivalent aMOOC performed in this work, which means a considerable difference.

With regard to the original contribution in this work about the participants' ability to create useful knowledge, Table 4 shows that there is a percentage of participants that consider the content contributed are very useful (strongly agree and completely 
agree) and exceeds $57 \%$ in TWCD, while in the other aMOOCs this value exceeds $70 \%$. Therefore, the users consider that they themselves have the capacity to generate useful knowledge. This perception confirms the contents contributed by the participants can improve the MOOC itself [1,9].

Regarding the perception of the application of the created resources by other participants in their daily activities, Table 7 shows that the vast majority of participants in the MOOC consider that other users' contributions (through the evaluation activities) are useful once the course is completed. Related to this, the $84 \%$ of the participants in TWCD select the maximum values of the scale (3 and 4) and exceeds $90 \%$ in the rest of the courses, reaching $95 \%$ in the case of FT.

The perception about the proposed adaptivity of the MOOCs is highly positive, two types of adaptivity were analyzed: adaptability to the different profiles (Table 5) and adaptation to the learning pace (Table 6).

Table 5 shows that the participants agree or strongly agree that the MOOCs of this project achieved adapting the learning resources to the participants' interests in a percentage higher than $82 \%$ in PFEI, while in the rest they exceed 94\%. Table 6 shows that more than $90 \%$ of the participants (in all aMOOCs) are very or completely agree with the adaptation to the learning rhythm of the MOOC didactic resources, thinking that it helped them in their learning. These results confirm these two indicators as elements of the adaptive construct for MOOCs that was validated in a previous work [12].

This work presents a prototype that has been tested and validated with more than 600 registered users. To implement this model with thousands of users, the analysis, classification, organization and use of the generated resources by the participants would be impracticable, so it is necessary to use a knowledge management system. The proposed technological framework already contemplates this possibility and in other study it has been applied successfully in the management of generated resources by the participants of a course [20].

\section{Conclusions}

As a general conclusion, it has been demonstrated the feasibility of the integration of MOOCs that allow the adaptivity of learning resources and activities (aMOOC) together with MOOCs that allow cooperation (hMOOC) to define the ahMOOCS. This integration has been shown to be useful for both to reduce dropout rates and to enable heterogeneous participants to produce useful resources to apply in their work context and to improve the learning resources of the ahMOOCs itself.

The ability to generate useful resources by the ahMOOC participants has been proved; thus, the need to use a knowledge management system that is in charge of classifying and organizing those resources has been justified. In this sense, diversity may be considered as a positive value for this kind of courses against the opinions that considered it as a negative issue. 
Likewise, it has been demonstrated that the adaptivity in the MOOCs opens a new field of research in the technological and conceptual models. It is shown that a xMOOC can combine overcrowding and personalization of learning.

This work has presented a prototype in operation, tested and validated by more than 600 users, but will continue to work on the validation of this work for MOOCs with more than 1000 participants. The work will also continue on integrating the different technologies that make up the different technological modules, extending asynchronous activities to other types of web 2.0 environments such as social networks.

\section{Acknowledgements}

This work has been partially funded by the Spanish Government Ministry of Economy and Competitiveness throughout the DEFINES project (Ref. TIN201680172-R).

We would like to thank the GATE Service of the Technological University of Madrid, the Government of Aragón and the European Social Funds for their support. Finally, the authors would like to express their gratitude to the research groups (LITI, http://www.liti.es; GIDTIC, http://gidtic.com and GRIAL, http://grial.usal.es).

\section{References}

1. Fidalgo-Blanco, Á., Sein-Echaluce, M.L., García-Peñalvo, F.J.: From massive access to cooperation: Lessons learned and proven results of a hybrid xMOOC/cMOOC pedagogical approach to MOOCs. International Journal of Educational Technology in Higher Education (ETHE) 13, 24 (2016)

2. Downes, S.. Stephen's Web. (2016) [Online]. Available: http://www/downes.ca/post/65696. [Accessed: 20-Febr-2017].

3. Adams Becker, S., Cummins, M., Davis, A., Freeman, A., Hall Giesinger, C., Ananthanarayanan, V.. NMC/Horizon Report: 2017 Higher Education Edition. The New Media Consortium, Austin, Texas (2017)

4. Berlanga, A.J., García-Peñalvo, F.J.: IMS LD reusable elements for adaptive learning designs. Journal of Interactive Media in Education 11, (2005)

5. Berlanga, A.J., García-Peñalvo, F.J.: Learning Design in Adaptive Educational Hypermedia Systems. Journal of Universal Computer Science 14, 3627-3647 (2008)

6. Sein-Echaluce Lacleta, M.L., Fidalgo-Blanco, Á., García-Peñalvo, F.J., Conde-González, M.Á.: iMOOC Platform: Adaptive MOOCs. In: Zaphiris, P., Ioannou, I. (eds.) Learning and Collaboration Technologies. Third International Conference, LCT 2016, Held as Part of HCI International 2016, Toronto, ON, Canada, July 17-22, 2016, Proceedings, pp. 380390. Springer International Publishing, Switzerland (2016)

7. García-Peñalvo, F.J., Griffiths, D.: Rethinking informal learning. In: Alves, G.R., Felgueiras, M.C. (eds.) Proceedings of the Third International Conference on Technological Ecosystems for Enhancing Multiculturality (TEEM'15) (Porto, Portugal, October 7-9, 2015), pp. 457-459. ACM, New York, USA (2015)

8. Griffiths, D., García-Peñalvo, F.J.: Informal learning recognition and management. Computers in Human Behavior 55A, 501-503 (2016) 
9. Fidalgo-Blanco, Á., Sein-Echaluce Lacleta, M.L., García-Peñalvo, F.J.: Methodological Approach and Technological Framework to break the current limitations of MOOC model. Journal of Universal Computer Science 21, $712-734$ (2015)

10. Nonaka, I., Takeuchi, H.: The knowledge creating company. Oxford University Press, New York, NY (1995)

11. Leris, D., Sein-Echaluce, M.L., Hernández, M., Fidalgo-Blanco, A. Relation between adaptive learning actions and profiles of MOOCs users. Fourth International Conference on Technological Ecosystems for Enhancing Multiculturality (TEEM'16) Salamanca 2-4 Noviembre 2016. ACM, New York, NY, USA. pp. 857-863. (2016)

12. Lerís, D., Sein-Echaluce, M.L., Hernández, M., Bueno, C.: Validation of indicators for implementing an adaptive platform for MOOCs. Computers in Human Behavior. In press (2016) http://dx.doi.org/10.1016/j.chb.2016.07.054

13. García-Peñalvo, F.J., Hernández-García, Á., Conde-González, M.Á., Fidalgo-Blanco, Á., Sein-Echaluce Lacleta, M.L., Alier-Forment, M., Llorens-Largo, F., Iglesias-Pradas, S.: Learning services-based technological ecosystems. In: Alves, G.R., Felgueiras, M.C. (eds.) Proceedings of the Third International Conference on Technological Ecosystems for Enhancing Multiculturality (TEEM'15) (Porto, Portugal, October 7-9, 2015), pp. 467-472. ACM, New York, USA (2015)

14. García-Peñalvo, F.J., Hernández-García, Á., Conde, M.Á., Fidalgo-Blanco, Á., SeinEchaluce, M.L., Alier-Forment, M., Llorens-Largo, F., Iglesias-Pradas, S.: Enhancing Education for the Knowledge Society Era with Learning Ecosystems. In: García-Peñalvo, F.J., García-Holgado, A. (eds.) Open Source Solutions for Knowledge Management and Technological Ecosystems, pp. 1-24. IGI Global, Hershey PA, USA (2017)

15. Moodle. Moodle web (2017) [Online],Available: http://moodle.org. [Accessed: 20-Febr2017].

16. PFEI. Video presentation. (2016). Retrieved on 02/18/2016. https://prezi.com/glu0pwhpnbc3/fundamentos-practicos-de-la-innovacion-educativa/

17. FT. Video presentation. (2016). Retrieved on 02/18/2016. $\mathrm{https}: / / \mathrm{www}$. youtube.com/watch? $\mathrm{v}=\mathrm{h} 3 \mathrm{~W} 1 \mathrm{nOD} 3 \mathrm{FRo} \&$ feature=youtu.be

18. LC. Video presentation. (2016) Retrieved on 02/18/2016. https://innovacioneducativa.wordpress.com/2015/11/10/como-utilizar-una-red-social-paraconstruir-una-comùnidad-de-aprendizaje/

19. TWCD. Video presentation. (2016). Retrieved on 02/18/2016. https:/innovacioneducativa.wordpress.com/2015/11/03/como-formar-y-evaluar-en-lacompetencia-de-trabajo-en-equipo-de-forma-sencilla-el-metodo-ctmtc/

20. García-Peñalvo, F.J., Fidalgo-Blanco, Á., Sein-Echaluce Lacleta, M., Conde-González, M.Á.: Cooperative Micro Flip Teaching. In: Zaphiris, P., Ioannou, I. (eds.) Learning and Collaboration Technologies. Third International Conference, LCT 2016, Held as Part of HCI International 2016, Toronto, ON, Canada, July 17-22, 2016, Proceedings, pp. 14-24. Springer International Publishing, Switzerland (2016) 